\title{
Investigative journalism in Mexico: between ideals and realities. The case of Morelia
}

\author{
Rubén Arnoldo GonZÁlez MaCíAS \\ Tecnológico de Monterrey, Campus Puebla (México) \\ rgonzalezm@itesm.mx
}

Recibido: 12 de mayo de 2015

Aceptado: 9 de noviembre de 2015

\begin{abstract}
The aim of this paper is to analyse the state of the investigative journalism in Mexico, especially the one that is practiced at the local level in the provinces. That is, this research is based upon a case study conducted in Morelia, the capital city of the state of Michoacán. The empirical evidence will show that there is an evident divergence regarding the practice of the investigative journalism: on the one hand, journalists are aware of what this concept involves and they consider that they practice it on a regular basis; but, on the other, the content analysis prove otherwise. In other words, the account of what is actually printed significantly differs from the news workers' perceptions, because the former shows a poorly developed journalistic investigation practice.
\end{abstract}

Keywords: Investigative journalism, Mexican media, instrumentalization, local press, professionalization.

\section{Periodismo de investigación en México: Entre ideales y realidades. El caso de Morelia}

\section{Resumen}

El objetivo de este artículo es analizar el estado del periodismo de investigación en México, especialmente el que se practica a nivel local en los estados. Es decir, en lugar de tomar en cuenta a la llamada prensa nacional (ubicada en la Ciudad de México, capital del país), la cual no necesariamente ofrece un panorama exacto de todo el país, esta investigación se basa en un estudio de caso realizado en Morelia, capital del estado de Michoacán. Los resultados muestran que hay una divergencia con respecto a la práctica del periodismo de investigación: Por un lado, los periodistas están familiarizados con dicho concepto y consideran que lo practican regularmente; pero, por el otro, un análisis de contenido muestra lo contrario. Por esta razón, lo que la prensa publica difiere significativamente de las percepciones de los reporteros.

Palabras clave: Periodismo de investigación, medios mexicanos, prensa local, instrumentalización, profesionalización.

\section{Standard Reference}

GONZÁLEZ MACÍAS, Rubén Arnoldo (2016): "Investigative journalism in Mexico: between ideals and realities. The case of Morelia". Estudios sobre el Mensaje Periodístico. Vol. 22, Núm. 1 (enerojunio), págs.: 343-359. Madrid, Ediciones Complutense.

Summary: 1. Introduction. 2. Investigative journalism and journalistic professionalization. 3. Methodology. 4. The findings: Investigative journalism according to local reporters; 4.1. Content analysis; 4.2. Other actors' opinions. 5. Discussion; 5.1. Levels of professionalization; 5.2. Instrumentalization of Mexican press. 6. Conclusions. 7. References.

\section{Introduction}

The relevance of investigative journalism is a widespread agreement amongst both reporters and academics. Thanks to its practice, the citizens can be informed in a deeper way about the issues that should matter to them and, thus, have a better understanding of their political, economic, social and cultural context. In order to do that, journalists are expected to go beyond the official statements and look for the 
other side of the stories they cover. Nonetheless, at least in Mexico, there is an evident gap between this ideal and every day practice. In other words, the Mexican case through the analysis of the local press in Morelia- shows that even though news workers acknowledge the importance of doing investigative reports, they actually do not do it as much as they think. Therefore, this paper presents the state of the investigative journalism in Morelia, the capital city of Michoacán, Mexico.

It is important to explain that the information presented here is part of a larger project focused on the analysis of the Mexican media system, which aimed to discuss on the changes and continuities of the journalistic practice (González, 2012). Based upon a case study conducted in Morelia, that study presents an explanation of the Mexican journalism structured at two levels: macro and micro. The former represents the local media system, which is the way news outlets are organised and operate (Hallin \& Mancini, 2004); and the latter is related to the nature and logic of the journalist-politician relationship (Blumbler \& Gurevitch, 1995, Pfetsch, 2004). Its central argument is that the media environment determines the way that news workers and their sources interact (González, 2012).

The concept of media system is integrated by the following set of parameters: firstly, the structure of media markets which represents the development of the media markets, especially the mass circulation press; secondly, the level of political parallelism or the partisan stance of both news organisations and journalists; thirdly the journalistic professionalization which is built upon the notions of autonomy, newsworthiness values, professional norms and public service orientation; finally, the role of the state is the involvement and intervention of the government in the mass communication production process (Hallin \& Mancini, 2004).

The parameter related to the journalistic professionalization was evaluated in that research through two specific factors: the practice of investigative journalism and the academic background of the local news workers (González, 2012). Thus, this paper offers an overview of the findings regarding the first factor. In that sense, the content of this article is organised in five sections: a brief survey of the literature on investigative journalism and journalistic professionalization, a description of the methodology of the study, an overview of the results, the discussion of those findings and some concluding remarks.

\section{Investigative journalism and journalistic professionalization}

For many years, scholars and practitioners have engaged in an endless debate regarding investigative journalism. On the one hand, there is a trend towards considering it as a specific field of the journalistic practice, with its own logic and standards. On the other, some people argue that, since this trade necessarily involves investigation (the process of gathering, verifying and analysing facts), every journalist is an investigative reporter then (Ettema \& Glasser, 1984; Reyes, 1996; Caminos, 1997).

These perspectives are neither right nor wrong per se, thus, accepting or refusing one of them is just a matter of opinion. The rationale behind the former relies upon the criticism towards the passivity of news workers, who are reactive rather than proactive. That is, more than actually reporting on events, they just collect press releases or 
sound bites. Under these circumstances, journalistic investigation is the exception, not the rule and, hence, it should be considered a specific category. On the contrary, advocates of the latter argue that investigation is inherent to journalism, because a professional coverage of an event requires - amongst other things - a context, a clear separation of facts and opinions and the inclusion of at least two sides of the story. In other words, routine journalism is by nature investigative journalism (Reyes, 1996; Caminos, 1997; Feldstein, 2007).

Beyond this simplistic debate, there are at least three factors that separate routine journalism from investigative journalism: time, depth and originality. A proper investigative special report demands longer periods of time than the daily routine reporting, because gathering, checking, contrasting and analysing reliable information cannot be done overnight. In that sense, due to the amount of facts and opinions, an investigative story is expected to offer a deeper understanding of the topic. Therefore, the final product is an original piece of journalistic work, which the rest of the news outlets will not have, because it is the result of the medium's own agenda (Reyes, 1996; Caminos, 1997; Feldstein, 2007).

Besides the concepts of time, depth and originality, the notion of conflict seems to be inherent to investigative journalism, just as much of the literature points out: this is a practice 'which scrutinises authority and delves into the failings of society' (de Burgh, 2003: 803). For that reason, this kind of reporters 'have to judge the information they obtain and make sure they have enough evidence to expose misdoings and to assign responsibility and blame' (Ekström, 2002: 271). In that sense, 'their explicit mission [is] to investigate beneath the surface and uncover hidden wrongdoing by powerful individuals and institutions' (Feldstein, 2007: 501).

Blumler \& Gurevitch (1995) called this type of relationship between reporters and sources the "adversary model". For a reporter shaped under this tradition, the real story is always hidden in politicians' words and acts. Therefore, his/her professional duty is precisely to uncover the truth that lies behind the official version. By adopting this creed, journalists consider themselves as holders of a special political power that must respond to the audience right to know. In short terms, the adversarial model is the fuel for the watchdog journalism, which main goal is to offer a surveillance service to citizens. The people, in their search for reliable information, delegate that responsibility to news organizations. The starting assumption which gives sense to this paradigm is that party and government institutions have a natural propensity to corruption, and since somebody has to watch them carefully, reporters need to be the first in line.

These 'idealised visions of the journalistic St George tracking down the political dragon' (Blumler \& Gurevitch, 1995: 29) have one thing in common: the idea that valuable information ought to be hidden from the public eye by the authorities and powerful groups. Therefore, the ultimate goal of investigative journalism is to expose the facts that someone wants to keep secret. Especially because that information is the proof that something is wrong (Caminos, 1997; Feldstein, 2006; Schudson, 2007).

As a result of exposing the hidden dirt of politics, investigative reporters are also known as "muckrakers", since they are very passionate about - even obsessed with the search of the dark side of hegemonic elites (Reyes, 1996; Feldstein, 2006 and 
2007). In so doing, and on behalf of the citizens, they assume the responsibility of keeping the people informed by responding to the so-called "right to know" of the latter. Notwithstanding, there is permanent risk of journalistic radicalization when news workers consider themselves judges instead of reporters. 'To be sure, the line between fair-minded investigative reporting and partisan witch-hunting or sensationalistic gossip-mongering can be a fine one, and it has been repeatedly crossed over the years' (Feldstein, 2006: 106).

On the other hand, it is worth presenting an overview of the concept of journalistic professionalization, which is important for outlining the core argument of the paper: the practice of investigative journalism in Morelia is not as developed as news workers think, because professional standards are more an ideal instead of a reality. Hence, professionalization and the practice of investigative journalism are interconnected issues.

'Professionalism connotes the exercise of autonomy, the right of workers to control their own work, frequently by reference to norms developed by professional agencies external to the organizations in which they work'(Tuchman, 1978: 65). Therefore, 'journalists learn what their organizations want by observation and experience... New journalists quickly learn what the boss likes from more experienced staffers' (Shoemaker \& Reese, 1996: 92). Since sharing and internalising particular routines within specific news organizations is the most important way of learning the trade, socialization is the key for understanding the journalistic professionalization then.

Furthermore, within the newsrooms the concept of a "professional" reporter also means being aware of what the rest of the media are doing. That is, he/she ought to monitor the news presented by other organizations for two reasons: firstly because if a news outlet publishes a story it means that its newsworthiness has already been judged by another journalist and, secondly, that story might as well become a "source" for other news (Schlesinger, 1978; Gans, 2004). Being professional, hence, is mainly valued by peers and colleagues rather than the audience. As a result of that, 'journalists forget that they are supposed to write for the readers and not for one another, which they tend to do more or less unconsciously' (Champagne, 2005: 56). For this reason, there is usually a divergence between the interests of the reporters and the interests of the citizenry at large (Schlesinger, 1978; Tuchman, 2002; Benson, 2006).

Considering the diversity of issues related to the concept of journalistic professionalization, Hallin \& Mancini (2004) propose a set of three dimensions to evaluate reporters' performance in this area. Although the three of them are closely connected with the concept of investigative journalism, especially the last two are directly related to this practice.

- Autonomy: as someone else's employees, journalists will never have a complete control over their work. Notwithstanding, an important degree of autonomy could be reached when they, as individuals and/or a collegiate group, by self-determination conciliate their own interests with the institution they work for.

- Distinct professional norms: reporters in a specific media system tend to share similar ethical principles such as the clear separation between advertising and editorial content, the protection of confidential sources or the common standards of newsworthiness. 
- Public service orientation: it represents the extent journalist are aware of their own role as civil servants, who need to show trustworthiness to their audiences, by providing them with accurate and useful information.

\section{Methodology}

In order to have a complete panorama of the state of investigative journalism in Morelia, a twofold methodology is required, which includes both quantitative and qualitative approaches. The former was a content analysis regarding political news and it focused on the amount of stories, agenda management and bias. The analysis included the five local newspapers (Cambio de Michoacán, El Sol de Morelia, La Jornada Michoacán, La Voz de Michoacán and Provincia), and was held from January to June 2010. Each newspaper's political section was revised every single day during the six months.

This period was selected for two reasons: firstly, because the interest was revising the published information in which the interviewed actors had certain degree of involvement at that time, either in generating or reporting it. Secondly, the idea was also to evaluate the political news production during a normal time. That is, not during an electoral campaign, when this kind of information has an excessive presence on the media and that might incline the results towards inaccurate parameters, which would not represent every-day reality. As Vliegenthart, Boomgaarden \& Boumans (2011: 98) noted, compared with electoral coverage, research on 'routine news periods' are scarce, even comparisons between both of them. Thus, looking at an ordinary period of time - when there are no elections near - provides useful insights of media routines (Gans, 2004).

The aim of using content analysis was to obtain empirical data related to the political messages that were published on a daily basis in the local newspapers. This information represents what actually was portrayed and framed by the media, not what the actors involved might have said about it. In that sense, the following table offers the sample of the content analysis, which represents the amount of political news published by each newspaper during the period of study (January-June 2010).

Table 1. Sample size of the content analysis

\begin{tabular}{|l|r|r|r|r|r|r|}
\cline { 2 - 7 } \multicolumn{1}{c|}{} & Cambio & El Sol & La Jornada & La Voz & Provincia & Total \\
\hline Political news & 1,760 & 1,534 & 1,356 & 1,403 & 1,400 & 7,453 \\
\hline
\end{tabular}

On the other hand, the qualitative approach included twenty in-depth interviews with political reporters/editors of each newspaper, politicians, state and local government communications officers, and state Congressmen/communications officers of the three main political parties, which at that time had $90 \%$ of the state Congress seats (Democratic Revolution Party 35\%, National Action Party 30\% and Institutional Revolutionary Party $25 \%$ ), whilst the rest hardly have any presence (Congreso del Estado, 2008). The interviewees were seven journalists, nine communications officers and four politicians. Due to a consent form signed by the informants before the interview, their identities will be kept anonymous and a specific combination of letters $(J$ for journalists, $C O$ for communications officers and $P$ for politicians) and numbers will be used whenever they are quoted. 
It is worth stressing that this paper considers the term 'investigative journalism' not as a particular category of special news stories, but in wider terms. That is, as it was mentioned in the literature review, there are two perspectives regarding this concept: firstly, it is considered as a specific kind of journalism and, secondly, simply as an adequately performed journalistic practice. Under this scheme, the findings will be analysed according to the latter. The rationale of this decision relies on the fact that, during the pre-test stage of the content analysis, it became evident the lack of investigative news stories published by the local press. Therefore, it was decided to evaluate this issue under the standards of the second perspective.

\section{The findings: Investigative journalism according to local reporters}

The aim of this section is to present the results of the fieldwork related to the practice of investigative journalism in Morelia. Due to the complexity of this issue, the content is organised in four subsections: Morelian journalists will define this concept in their own terms. Secondly, based upon their answers, it will be presented an overview of the frequency of this practice at the local level. The third part of the section includes the content analysis findings. Finally, in order to offer a different perspective, politicians and communications officers will evaluate local reporters' performance in terms of investigative journalism.

An important part of media's public service orientation is the practice, on a regular basis, of the investigative journalism norms. However, it is important to stress that its practice, as the interviewees acknowledged, is not exclusive of the political beat. Since 'investigation assumes that some of the information that is important to citizens is not normally visible to them and may be deliberately hidden from them' (Schudson, 2007: 140), local reporters in Morelia are also aware of its importance for their readership. Nevertheless, as the findings will show, the frequency of its use is not exactly as high as they claimed and, as a consequence of that, newspapers are easy prey of instrumentalization by the political actors. In other words, the lack of investigative journalism fosters a significant dependence on the official version and, hence, the agenda management process is clearly dominated by government and party leaders; who use media as their internal mail.

$J 2$ considered that 'investigative journalism means going beyond the daily news. It is choosing a theme and keep on following it during a period of time'. Therefore, $J 7$ stressed that this kind of reporting is not solely built upon covering a current event, it implies presenting a more complete view of the complexity of that event. In so doing, as $J 5$ argued, three main aspects are needed: documents and/or evidence, at least three sources of information or versions, and enough time to gather, organise and write the facts. $J 4$ and $J 6$ added that the documentation required must explain the context of the issue, both historical and current. The investigative story should offer enough testimonies and anecdotes of the actors involved as well. For that reason, it is very important to have and contrast different opinions from specialists, government officers, academics and citizens.

'Investigation comes from our own agenda, it is the information that this newspaper produces and will not be found in any other news outlet. This is what makes us different from the rest', $J 1$ said. This interviewee also explained that, through press 
releases or statements, government and companies try to emphasise their virtues or what is important for achieving their own goals. In that sense, investigative journalism promotes a wider vision of reality, where different opinions converge and not only the official version. Notwithstanding, reporters are not supposed to do this just for a personal revenge or because someone is paying them for it. In both cases, their objectivity is at stake: for the former, the information will tend to be excessively unfavourable and, for the latter, very friendly. That is why, $J 1$ concluded, investigation is not only related to 'what is wrong' (corruption, scandals, crime...), it might as well be about 'what is right' (political achievements, economic development...) $)^{1}$ That is, something that has a real social impact, otherwise it is meaningless.

In Michoacán there is a misunderstanding about what investigative journalism is. Many reporters think that it is just writing about the organised crime or drug cartels, but they seem to ignore that it might be about any field they would like to write about (J2).

According to the interviewee, editors should not impose the topics for the investigations, it has to be journalist's decision instead. It is better when the reporter decides about his/her story, because it is only him/her who perceives the pulse of the sources, he/she knows all the underground issues that 'the politicians do not want them to be public'. Even an editor with good connections and with a good relationship with reporters, would never be fully involved with every single source. Due to the inherent demands of the profession, $J 5$ explained that this practice should not only be constrained by long term investigations, because reality runs faster than any plan and the reporter needs flexible strategies to cover the stories. For that reason, this interviewee's suggestion is that investigative journalism ought to be done 'on the go', as the social or political juncture unfolds.

This informant also perceived that local investigative journalism is now entering into a new stage, thanks to the internet and the new laws of transparency and information access. Both of them are tools that old journalists did not have, but the problem is that the new ones do not use them as much as they could either. Especially the latter is not very used because the bureaucratic process of asking and getting official data is long and difficult. Even more, sometimes the information provided is not complete or simply denied without further explanations. However, $J 3$ pointed out that the ideal conditions for practicing it are absent most of the times, because no local newspaper gives its reporters enough time and money to do it. Here is when, rather than a specific category, investigative journalism becomes routine journalism:

It does not mean that in your daily work you do not cover the topics in depth, because investigation is inherent to your job. Hence, doing investigative journalism under the ideal conditions is not possible, because there are not such conditions, but you have to do it anyway. Despite your newspaper's limitations - and yours - you do it, you go there, ask questions and get the information. Finally, the lack of resources makes you find your wiles.

1 The tendency to emphasise the "wrong" to the detriment of the "right" is not exclusive of Morelian press. Patterson (2000:14) concluded that, instead of partisanship, American journalists show 'a pronounced tendency to report what is wrong with politics and politicians rather than what is right'. 
Related to this point, $J 2$ explained that the difficulties of practicing it are directly linked to the information production chain. Local reporters are expected to submit between three and five news stories every day and their income tends to be low (460-560 USD per month), so they can hardly reach their daily quota and they do not feel any motivation to do something that requires an extra effort. Besides the journalists' hard professional conditions, media directors-general have a lot to do with this problem too: 'none of the local newspapers directors-general is actually a journalist. All of them are businessmen and they do not understand how difficult it is to get good information. They are more interested in quantity than quality'. Despite all the limitations, $J 5$ insisted on the importance of this practice: 'investigative journalism has helped forge my name, because respect and credibility are built up day-by-day'. Even though the readers do not care who wrote the story, it is important for the peers' recognition, since reporters are mainly evaluated in the newsrooms, both theirs and their competitors (e.g. Tuchman, 1972; Shoemaker \& Reese, 1996; Champagne, 2005).

\subsection{Content analysis}

In order to evaluate the levels of investigative journalism of the local printed media, content analysis measured the number and type of sources they normally use and the political actors whom the news talks about. It is important to stress that, rather than "special reports", this paper considers "investigative journalism" as the correct practice of routine reporting. It is also worth reminding that the following figures come from the review of the news stories published in the political sections of the five newspapers during the period of January-June 2010. Contrary to what journalists said about the importance of the investigative journalism and its frequent practice, the findings showed a divergent perspective.

As it was commented before, one of the minimal requirements for practicing it is to offer at least two sides of the story (more than one source of information), which was not the case in most of the news published during the period of study. Nevertheless, this situation is consistent with a recent study on journalism cultures in Mexico, Chile and Brazil, which concluded that 'several results that turned out to be contradictory could be understood as an internal struggle between what the journalists feel they should do (or want to do), and their everyday practice' (Mellado, Moreira, Lagos \& Hernández, 2012: 74). Therefore, the following chart offers a rather different version of what the interviewees of this study mentioned:

Chart 1. Number of sources used by Morelian newspapers (Personal compilation)

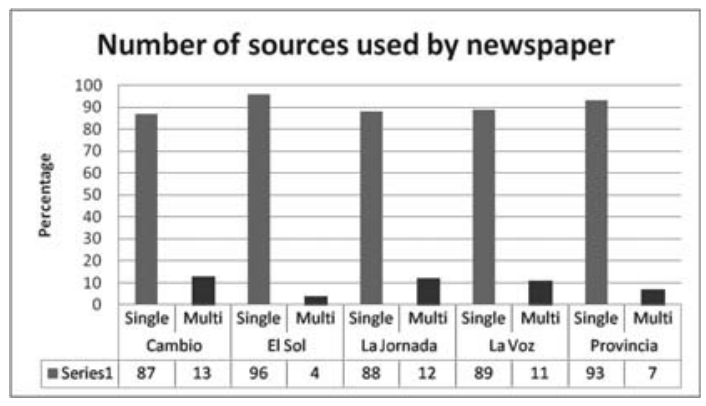

Sample of news stories:

- Cambio: 1,760

- El Sol: 1,534

- La Jornada: 1,356

- La Voz: 1,403

- Provincia: 1,400 
The chart speaks for itself: there is an evident lack of different opinions and versions in the news that the local printed media offer to their readership. Nearly all of the stories rely only on a single source of information, which means that doing investigation is not exactly the newspapers' top priority. It is worth explaining that number of sources represents the different versions included in a news story, which could be single (only one side) or multi (two or more sides of the story).

As the following chart will show, a common practice in Morelian media is covering an official event, which is an activity organised by government officials or political parties' leaders for publicising their achievements (opening new facilities, providing economic resources for peasants, appointing new cabinet members...) or sharing their opinions. Since a lot of important actors attend this kind of activities, reporters can collect several opinions regarding the central issue of the event or other topic of the public agenda. But all of those voices represent only one version or side, because the attendants belong to the same group (businessmen, high rank officials, members of interest groups and so on). Nonetheless, alternative voices are absent in the news simply because they were absent at the event.

For a better understanding of this point, the next chart breaks down the concept of source, which represents the different ways that the local reporters use for obtaining information. These sources are basically press releases and conferences, exclusive interviews, official events coverage, unofficial source (leaks, rumours or anonymous informants) and the newspapers' own investigation (the stories which are the product of their own agenda). As these figures will show, the significance of measuring the frequency of use of different sources news workers rely on is that their reporting routines become clearer.

Chart 2. Type of sources used by Morelian newspapers (Personal compilation)

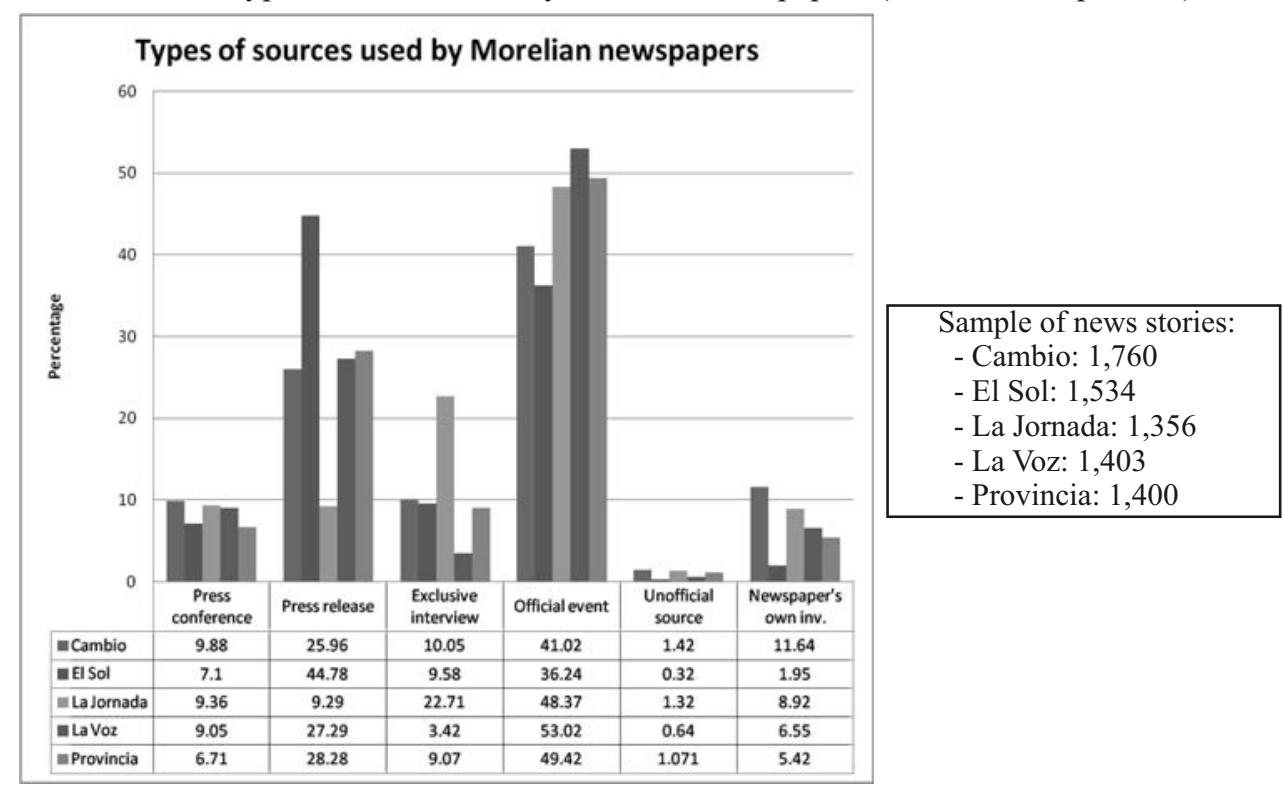


As shown on the very first chart (number of sources), Cambio is the local newspaper which has the highest rate of different sources of information (13\%) and, as a result of that, it has the highest rate of own investigation (11.64\%), whilst El Sol shows the poorest results in these issues: $4 \%$ in multi sources news and $1.95 \%$ in own investigation. Thus, there is a direct correlation between the number of sources and the prominence of the media's investigative work: the wider the diversity of information used for the stories, the more frequent is the practice of the investigative journalism canons.

There is an evident trend in covering press conferences, because the rates for all the media outlets oscillates between $6.71 \%$ (Provincia) and 9.88\% (Cambio), having a distance between the highest and lowest of only $3.17 \%$. Another aspect that shows homogeneity is that unofficial sources (leaks, rumours, anonymous informants...), are not widely used by anyone: a little bit above of $1 \%$ is the difference between the highest (Cambio, 1.42\%) and the lowest ( $\mathrm{El} \mathrm{Sol,} \mathrm{0.32 \% ).} \mathrm{Although} \mathrm{the} \mathrm{intermediate} \mathrm{rates}$ are consistent, the highest and lowest peaks of three issues are very distant from each other: related to the use of press releases, there is a $35.39 \%$ gap between $\mathrm{El} \mathrm{Sol}$ (44.78\%) and La Jornada (9.29\%). For the case of the exclusive interviews, the distance between the highest (La Jornada, 22.71\%) and the lowest ( $\mathrm{a} \mathrm{Voz,3.42 \% )}$ is $19.29 \%$. Related to the official event coverage, the gap is $16.78 \%$, where $\mathrm{La} \mathrm{Voz}$ has the highest rate (53.02\%) and $\mathrm{El} \mathrm{Sol}$ the lowest (36.24\%).

Closely connected with the concept of source is the issue of the actors involved in the news, which are the figures who participate in the political arena and whom the news talk about. Thus, the following chart shows the political actors and their presence during the period of study, measured by the percentage of mentions on the news stories.

Chart 3. Political actors in Morelian newspapers (Personal compilation)

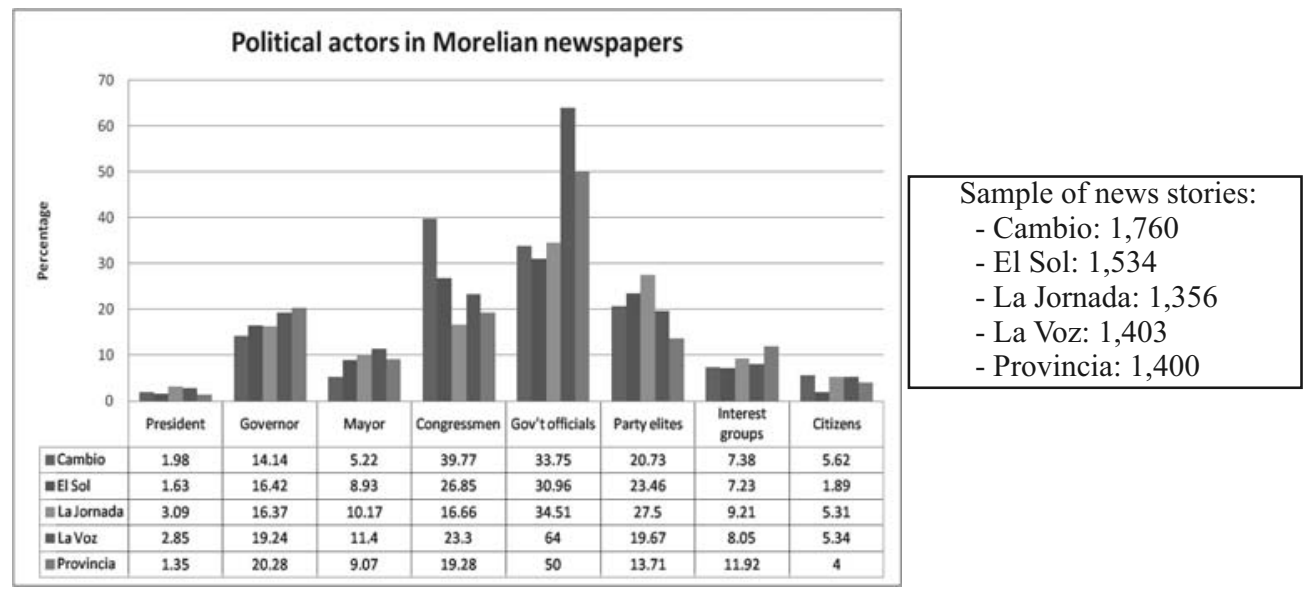

Prior to the explanation of the results, it is important to stress that the percentages indicated in the last chart are individual frequencies, thus their sum is not $100 \%$. The reason is because the news stories do not always include only a single political actor, on the contrary, one story may talk about two or more of them. Hence, the number 
refers to the amount of times the actor was mentioned, but it does not mean that he/she was the only one in that particular news. In statistical terms, when more than one item could be accepted as a valid answer in a single question, each item should be measured individually.

The political actors included in the charts might be organised in three categories: individual actors (president, governor and mayor), groups (Congressmen, government officials -federal, state or local- and party elites) and others (interest groups and citizens). Regarding the individual political actors, there is a neat homogeneity in the way newspapers covered the president, governor and mayor. All the media outlets showed the same trend: the governor had always highest levels of presence in the news, followed by the mayor and, far from them, the president had the lowest coverage. In terms of rates, the governor oscillated between 20.28\% (Provincia) and $14.14 \%$ (Cambio), the mayor 11.4\% ( $\mathrm{La} \mathrm{Voz}$ ) and 5.22\% (Cambio), and the president $3.09 \%$ (La Jornada) and $1.35 \%$ (Provincia). Another neat homogeneity appeared in the way interest groups and citizens were covered. All the newspapers presented the same trend: the former got better presence (between $11.92 \%$ in Provincia and $7.23 \%$ in $\mathrm{El}$ $\mathrm{Sol}$ ) than the latter (between 5.62\% in Cambio and 1.89\% in El Sol).

A different situation appeared when newspapers covered the diverse groups of political actors. El Sol, La Voz and Provincia presented the same trend: government officials had the highest rates, followed by Congressmen and party elites. Cambio and La Jornada showed different patterns: for the former, the tendency was Congressmen, government officials and party elites and, for the latter, it was government officials, party elites and Congressmen. Despite their ranking in each news organization, government officers got a good coverage: between 64\% ( $\mathrm{La} \mathrm{Voz})$ and 30.96\% ( $\mathrm{El} \mathrm{Sol}$ ). Congressmen and party elites had a fair presence: between 39.77\% (Cambio) and $16.66 \%$ (La Jornada) for the former, and between 27.5\% (La Jornada) and 13.71\% (Provincia) for the latter.

\subsection{Other actors' opinions}

This part of the section presents the viewpoints of communications officers and politicians regarding Morelian media's performance. When they were asked to evaluate the local press, they all raised the issue of investigative journalism. Their opinions are empirically useful and valid because the interviewees are either former journalists or highly informed news consumers. In other words, communications officers have a significant journalistic background and, thus, their expertise allow them to provide a solid argument about this issue. On the other hand, and even though politicians are not expected to be "media experts", they are directly involved in the news-making process as information sources, plus they are heavy consumers of information. Therefore, just as the formers', the latters' points of view contribute to the overall analysis of the local investigative journalism practice.

Interviewees' answers pointed at an evident agreement: newspapers in Morelia are not practicing this kind of reporting. 'Journalism is much more than collecting politicians' opinions, there is a lack of investigation here. There is no such thing as investigative journalism in Michoacán, nobody does that', $\mathrm{CO} 3$ said. The reason is that 
reporters are only worried about going to official events to get participants' reactions. They do not look for any extra information. CO5, a former journalist, insisted on the same point:

Local media need to do more investigation, because that could boost their own agenda and their stories might have a deeper impact inside the Congress or state government... Local journalism only runs after current events. Daily news is that: what the politician or public officer said, it is not information sought by reporters.

According to $\mathrm{CO} 4$, there must be more investigation in the local press, which means more documentation. The news should not only rely on a single comment or opinion, nor using unreliable sources. Hence, reporters have to look for more facts or figures, not just depending on the press release. Therefore, "press release dependence" is only one of the main factors that impede the transformation of local media, because their personnel wait until the very last minute to get the official statement from the press office. 'Is not that they want the story or they want to have more details', as $P 4$ pointed out.

This interviewee also suggested that sometimes correspondents harshly criticise public servants not just because they were ordered to or for personal reasons, but because of the lack of another version. If they only rely on one side of the story, the other side may become invisible or mute then. Nevertheless, the origin of this poor work is not always the reporters' fault. $C O 1$, another former journalist, explained that most of the times media's routines do not allow them to do more than that. Since reporters have a specific news quota, it is impossible for them to have the chance to find every actor involved and offer a more complete story, and even do it on a daily basis.

Finally, even though this point will be addressed in next section, $\mathrm{CO} 7$ considered that official advertising contracts are also behind the lack of investigative journalism: 'a lot of the information that media in Michoacán publish comes from official advertising contracts, the official version, and most of the times they neglect other issues... Only few of them have a clear editorial line and offer balanced information'.

\section{Discussion}

The implications of the findings will be analysed in this section. In so doing, the content is divided in two parts: the first one will present an evaluation of the journalistic professionalization of local reporters based upon Hallin \& Mancini's (2004) parameters of autonomy, distinct professional norms and public service orientation. On the other hand, through the Morelian case, the second part offers a discussion on the instrumentalization of the Mexican news outlets by the State government.

\subsection{Levels of professionalization}

Regarding the levels of journalistic professionalization explained earlier, Hallin \& Mancini (2004) suggested a set of three parameters for evaluating this issue, which include autonomy, distinct professional norms and public service orientation. According to the data collected from the field, this is Morelian reporters' performance:

- Autonomy: even though this issue will be stress further in the following subsection, official advertising is the main coercion factor that determines how au- 
tonomous media and their staff could be. It means that political information coverage and framing is openly shaped by this element. To a lesser degree, some of the interviewees commented off the record that drug cartels also have an impact on news outlets, because they have become a strong power stakeholder which has its particular means of "persuasion".

- Distinct professional norms: as the content analysis proved, and reinforced by the interviews too, there is a lack of investigative journalism in Morelia fostered by an evident dependence on press releases and official events coverage. This situation promoted the use of only one version of reality, neglecting the other side of the story.

- Public service orientation: related to the last points, it could be said that the civic orientation that Lawson (2002) and Hughes (2006) found in their studies of Mexican news organizations is not the common rule here. In part due to the reasons explained just before, but also because of the lack of citizen presence in the local news which, by the way, reinforces the general absence of the public in the news stories around the world. In other words, regular people are nearly non-existent for local printed media - as the content analysis demonstrated - since they are basically portrayed as victims of a tragedy or recipients of a government programme.

In sum, the empirical evidence supports the argument of the low levels of professionalization in the local media system; which is characterised by a reduced autonomy towards the government and other political actors (as a result of a high official advertising dependence), lack of investigative news reports, and an almost invisible citizen representation due to a poor public service reporting orientation. Just as it was mentioned earlier, these three aspects are related to the concept of investigative journalism, but especially the last two which are, indeed, the core of this journalistic practice. It was also commented that there are different ways to evaluate media's professionalization, but this paper relies upon Hallin \& Mancini's framework, which proposes this approach. Nonetheless, it cannot be said that professionalization and investigative journalism are synonymous, but they are clearly interdependent. That is, the adequate practice of the latter-considered either as a specific category or just as a routine exercise- foster the former.

\subsection{Instrumentalization of Mexican press}

This part of the section offers the argument regarding the instrumentalization of the Morelian media organizations by the state government, a situation that becomes evident by analysing the local investigative journalism practices. Therefore, a clear obstacle to journalistic professionalization is instrumentalization, which can be defined as the control that external actors might exert over the media, in order to intervene in the political communication process. Those outsiders can be government institutions, political parties, interests groups, and other kind of organizations which seek political influence (Hallin \& Mancini, 2004). But not only political reasons foster this situation, commercial purposes threaten media as well, and even both of them simultaneously. 
Through the advertising budget pressure, the editorial content may be frequently pushed to certain directions that were not originally planned (González, 2013).

Obviously, to the extent media organizations are instrumentalised in this way, professionalization will be low: journalists will lack autonomy, political rather than distinctively journalistic criteria will guide the practice of journalism, and media will serve particular interests rather than functioning as a public trust (Hallin \& Mancini, 2004: 37).

Regarding the Mexican case, this situation was the main feature of the Institutional Revolutionary Party (PRI) regime that ruled the country during seventy years. In terms of control of the media, this regime developed mastery in using soft means of coercion, such as bribery, newsprint access and recently official advertising allocation (Bohmann, 1986; Trejo, 1992; Rodríguez, 1993; Lawson, 2002; Hughes, 2006; González, 2013). At the local level in Morelia, the empirical evidence showed that in spite of the arrival of a different political party to the state and local administrations, the use of the news outlets as the internal mail of the high rank officials and party elites is still the hallmark of the media system in this city.

'Although studies do give prominence to primary definers as shapers of news content, few have concluded that journalists are mere stenographers of power' (Covert \& Washburn, 2007: 69). Following this assumption and as commented earlier, local reporters in Morelia are not particularly keen on investigative journalism principles, because they actually do not need them in order to do their job. Since most of the government officials and politicians are more than ready to provide information to reinforce their own images or weaken someone else's, political correspondents just have to make phone calls or drop by the press offices to get ready to print statements (Márquez, 2012; Reyna, 2014).

In order to explain the Mexican media system, and Morelian as well, an instrumentalist model suits best (Hallin, 1995). This is because there is a direct control over the content of the news by government and political elites which, in agreement with owners and editors, shape the information that is going to be published or broadcasted. Under these circumstances, there is a permanent risk of instrumentalization when local media personnel, instead of actually being journalists, willingly or forced they only act as government spokespersons by parroting official statements.

Instrumentalization, hence, is one of the key features for understanding Morelian political journalism, which suffers from a "press release-dependence". By simply reproducing the official version, without presenting different sides of the story or even giving follow-up, news organizations are frozen in the PRI regime time, when the head of the administration - whether federal or state - used to dictate the headlines (Bohmann, 1986; Trejo, 1992; Rodríguez, 1993). Since 'the government's spin is gospel' (Castañeda, 1997: 138), then, it is not a surprise that 'pro-government self-censorship continues to characterise much of the printed press, especially in the provinces' (Orme, 1997: 16). In sum, and as a reflection of Mexico, Morelian journalistic practice could be considered as 'loyal and opportunist' because 'it tends to defend authorities, and serves as a messenger for the political and economic elite' (Mellado, Moreira, Lagos \& Hernández, 2012: 63). 
Therefore, the practice of investigative reporting -or the lack of it- depends to an important extent on the commercial agreements between media owners and government authorities. In other words, more than a public service tool, it is used as a means of coercion towards politicians, because media owners ask their journalists to do investigative reports in order to harshly criticise a specific public servant. After the story -or even a series of stories- is published, an official advertising contract is signed between the news outlet and the politician (González, 2013).

\section{Conclusions}

The practice of investigative journalism in Morelia oscillates between ideals and realities, because reporters acknowledge its importance and they consider they practice it on a regular basis; but, on the other hand, the stories that are published by the local newspapers showed an evident lack of it, and even their sources agreed that news workers actually do not do any investigation. Thus, due to pro-government publications with nearly identical political coverage, Morelians do not have reliable and trustworthy information sources, which could help them to understand their historical moment and keep public servants accountable. In other words, since there is no such thing as investigative journalism, newspapers are mere government messengers, because the clientelistic environment promotes this practice. Therefore, the idea of the transformation of media in Mexico is challenged by the evidence of the same old journalistic practice, determined by an overt instrumentalization exerted by the government and the lack of investigative journalism.

\section{References}

BENSON, Rodney (2006): "News media as a "journalistic field": What Bourdieu adds to New Institutionalism, and vice versa". Political Communication, 23 (2), pp. 187-202.

BLUMLER, Jay G. \& GUREVITCH, Michael (1995): The crisis of public communication. London, Routledge.

BOHMANN, Karin (1986): Medios de comunicación y sistemas informativos en México. México, Alianza Editorial.

CAMINOS, José M. (1997): Periodismo de investigación: Teoría y práctica. Madrid, Síntesis.

CASTAÑEDA, Jorge G. (1997): "Limits to Apertura: Prospects for press freedom in the new free-market Mexico". In ORME, William A. (ed.): A culture of collusion. An inside look at the Mexican press (pp. 133-140). USA: North-South Center Press.

CHAMPAGNE, Patrick (2005): "The "double dependency": The journalistic field between politics and markets". In BENSON, Rodney \& NEVEU, Erik (Eds.): Bordieu and the journalistic field (pp. 48-63). UK: Polity Press.

CONGRESO DEL ESTADO (2008): Integrantes de la LXXI legislatura del Estado de Michoacán de Ocampo. Retrieved November, 2009, from http://congresomich .gob.mx/cur_diputados/integrantes\%20todos.php 
COVERT, Tawnia A. \& WASHBURN, Philo C. (2007): "Information sources and the coverage of social issues in partisan publications: A content analysis of 25 years of the Progressive and the National Review". Mass communication and society, 10 (1), pp. 67-94.

DE BURGH, Hugo (2003): "Kings without crowns? The re-emergence of investigative journalism in China". Media, Culture \& Society, 25, pp. 801-820.

EKSTRÖM, Mats (2002): "Epistemologies of TV journalism: A theoretical framework". Journalism, 3 (3), pp. 259-282.

ETTEMA, James S. \& GLASSER, Theodore L. (1984): "On the epistemology of investigative journalism". Paper presented at the Annual Meeting of the Association for Education in Journalism and Mass Communication. Gainesville, Florida, August.

FELDSTEIN, Mark (2006): “A muckraking model: Investigative reporting cycles in American history". The Harvard International Journal of Press/Politics, 11 (2), pp. 105-120.

FELDSTEIN, Mark (2007): "Dummies and ventriloquists: Models of how sources set the investigative agenda". Journalism, 8 (5), pp. 499-509.

GANS, Herbert J. (2004): Deciding what's news. A study of CBS Evening News, NBC Nightly News, Newsweek and Time. USA, Northwestern University Press.

GONZÁLEZ, Rubén Arnoldo (2012): Change and continuity in Mexican journalism. The case of Morelia (PhD thesis). Leeds, UK, University of Leeds.

GONZÁLEZ, Rubén Arnoldo (2013): "Economically-driven partisanship. Official advertising and political coverage in Mexico: The case of Morelia". Journalism and Mass Communication, 3 (1).

HALLIN, Daniel C. \& MANCINI, Paolo (2004): Comparing media systems. Three models of media and politics. USA, Cambridge University Press.

HALLIN, Daniel C. (1995): "Dos instituciones un camino: Television and the State in the 1994 Mexican election". Paper presented at the XIX Annual Congress of the Latin American Studies Association, Washington DC, September.

HUGHES, Sallie (2006): Newsrooms in conflict. Journalism and the democratization of Mexico. USA, University of Pittsburgh Press.

LAWSON, Chapell H. (2002): Building the fourth estate. Democratization and the rise of a free press in Mexico. USA, University of California Press.

MARÍN, Carlos (2003): Manual de periodismo. México, Grijalbo.

MÁRQUEZ, Mireya (2012): "Valores normativos y prácticas de reporteo en tensión: percepciones profesionales de periodistas en México". Cuadernos de Información, 30, pp. 97-110.

MELLADO, Claudia; MOREIRA, Sonia V., LAGOS, Claudia; \& HERNÁNDEZ, María E. (2012): "Comparing journalism cultures in Latin America: The case of Chile, Brazil and Mexico". The International Communication Gazette, 74 (1), pp. 60-77. 
ORME, William A. (1997): “Overview: from collusion to confrontation". In ORME, William A. (ed.): A culture of collusion. An inside look at the Mexican press (pp. 1-17). USA, North-South Center Press.

PATTERSON, Thomas E. (2000): Doing well and doing good: How soft news and critical journalism are shrinking the news audience and weakening democracyAnd what news outlets can do about it. USA, Joan Shorenstein Center on Press, Politics, and Public Policy, Kennedy School of Government, Harvard University.

REYES, Gerardo (1996): Periodismo de investigación. México, Trillas.

REYNA, Vícor Hugo (2014): Nuevos riesgos, viejos encuadres: la escenificación de la inseguridad pública en Sonora. México, El Colegio de Sonora.

RODRÍGUEZ, Rafael (1993): Prensa vendida. México, Grijalbo.

SCHLESINGER, Philip (1978): Putting "reality" together. BBC News. UK, Constable.

SCHUDSON, Michael (2007): "The concept of politics in contemporary US journalism". Political Communication, 24 (2), pp. 131-142.

SHOEMAKER, Pamela \& REESE, Stephen D. (1996): Mediating the message. Theories of influences on mass media content. USA, Longman Publishers.

TREJO, Raúl (1992): La sociedad ausente. Comunicación, democracia y modernidad. México, Cal y Arena.

TUCHMAN, Gaye (1972): "Objectivity as a strategic ritual". American Journal of Sociology, 77 (4), pp. 660-679.

TUCHMAN, Gaye (1978): Making news. A study in the construction of reality. USA, The Free Press.

TUCHMAN, Gaye (2002): “The production of news". In JENSEN, Klaus B. (ed.): A handbook of media and communication research. Qualitative and quantitative methodology (pp. 78-90). USA, Routledge.

VLIEGENTHART, Rens; BOOMGAARDEN, Hajo G.; \& BOUMANS, Jelle W. (2011): "Changes in political news coverage: Personalization, conflict, and negativity in British and Dutch newspapers". In BRANTS, Kees \& VOLTMER, Katrin (Eds.): Political communication in postmodern democracy: Challenging the primacy of politics (pp. 92-110). UK, Palgrave McMillan.

Rubén Arnoldo González Macías es periodista, docente e investigador. Es licenciado en Ciencias de la Comunicación, máster en Comunicación por la Universidad Vasco de Quiroga (Morelia, Mich.) y doctor (PhD) en Estudios de la Comunicación por la Universidad de Leeds (Reino Unido). Ha sido reportero, editor y jefe de investigación en el periódico La Voz de Michoacán. Su trabajo académico ha sido presentado y publicado tanto en México como en Europa y Sudamérica. Actualmente es profesor de tiempo completo en el Departamento de Mercadotecnia, Comunicación y Arte Digital del Tecnológico de Monterrey, Campus Puebla (México). 